\title{
Granuloma Gluteale Infantum: A Case Report
}

\author{
Raymond de Zeeuw, M.D.,* Marinus C. G. van Praag, M.D.,* and Arnold P. Oranje, M.D.† \\ *Department of Dermatology, Sint Franciscus Gasthuis, Rotterdam, The Netherlands, and $†$ Department of \\ Dermatology and Venereology, Erasmus University and University Hospital, Rotterdam, The Netherlands
}

\begin{abstract}
Granuloma gluteale infantum is a benign disorder with the clinical appearance of "granulomatous" nodules involving the diaper area. It is an uncommon disorder considered a complication of primary irritant diaper dermatitis. A 6-month-old boy with reddish-purple oval nodules located on the right inguinal fold and right buttock diagnosed as granuloma gluteale infantum is presented. A contributing factor in our patient could be a primary irritant dermatitis or a preexisting candidial infection. The name granuloma gluteale infantum is a misnomer since no granulomas are found in these lesions.
\end{abstract}

Granuloma gluteale infantum was first described by Tappeiner and Pfleger in 1971 (1). They reported six healthy infants with a "granulomatous" eruption involving the gluteal region. The pathogenesis of these lesions is not clear; primary irritant dermatitis, plastic pants, the use of topical corticosteroids, and candidial infection have been postulated as possible etiologies. The lesions have a characteristic clinical appearance: oval, reddishpurple nodules of different sizes $(0.5-3.0 \mathrm{~cm})$ occurring on the convexities of the diaper area in 2- to 9-month-old infants with a history of diaper dermatitis. They resolve without treatment.

\section{CASE REPORT}

A 6-month-old boy with a 4-week history of reddishpurple lesions in the diaper area was referred by a general practitioner for consultation. One month before these lesions appeared, our patient had diaper dermatitis caused by a culture proven Candida albicans infection, but this had been mild and responded very well to miconazol $2 \%$ in zinc oxide paste. The candidial diaper dermatitis cleared completely, but 4 weeks later several new lesions developed on the right inguinal fold and right buttock.
Physical examination revealed three reddish-purple oval nodules $2-3 \mathrm{~cm}$ in size located on the right inguinal fold and one nodule on the right buttock (Figs. 1 and 2). A $4 \mathrm{~mm}$ biopsy specimen was taken and histologic examination showed mild acanthosis with orthokeratosis and a dense, superficial and deep dermal infiltrate (Fig. $3)$. The infiltrate consisted of numerous lymphocytes, histiocytes, and plasma cells, with focal aggregates of neutrophils and eosinophils forming microabscesses. Giemsa staining showed an increase in mast cells. There was endothelial swelling but no sign of vasculitis. No fungal elements were demonstrated with PAS staining.

The diagnosis of granuloma gluteale infantum was made based on the clinical and histologic features. Treatment consisted of topical zinc oxide paste. After a follow-up period of 2 months the lesions regressed, leaving residual, brownish-pigmented spots.

\section{DISCUSSION}

Granuloma gluteale infantum is characterized by large, firm, reddish-purple, oval or elongated nodules and plaques appearing on the inguinal folds, scrotum, but-

Address correspondence to R. de Zeeuw, M.D., Kleiweg 500, 3045 PM Rotterdam, The Netherlands. 


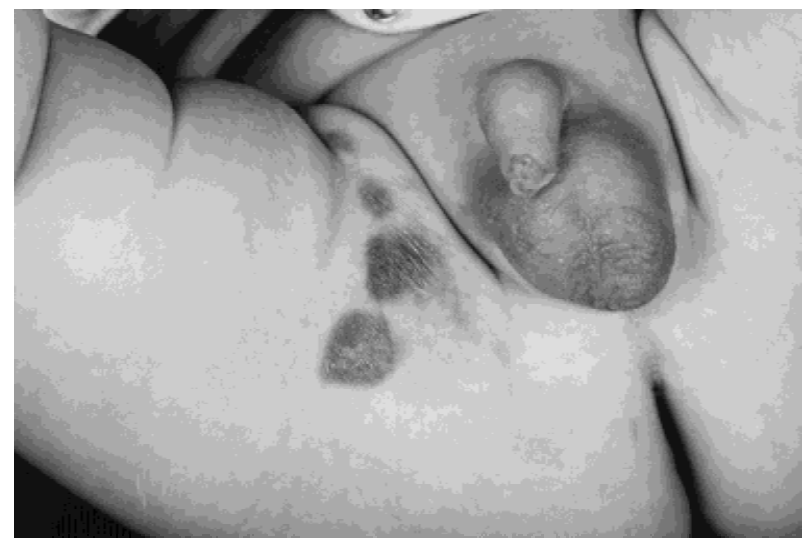

Figure 1. Three reddish-purple oval nodules on the right inguinal fold.

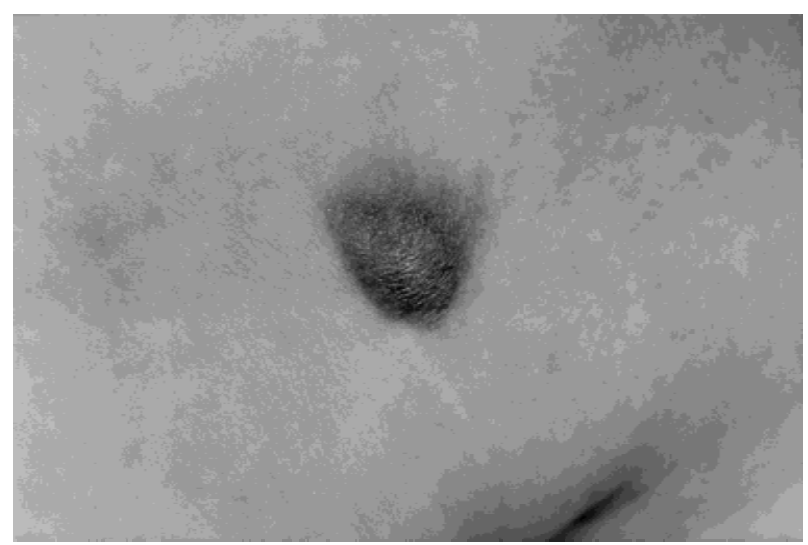

Figure 2. One nodule on the right buttock.

tocks, and medial aspect of the thighs. Usually this condition is seen in infants between 2 and 9 months of age. As with the cases of Tappeiner and Pfleger (1) and Bonifazi et al. (2), the lesions in our patient tended to occur on the convexities of the diaper area where there was maximum contact with the diaper. The lesions are not exclusively localized in the gluteal region, and have been described in the axillae and neck region (3).

The clinical differential diagnosis includes mastocytoma, juvenile xanthogranuloma, Langerhans cell histiocytosis, scabietic nodules, leukemic infiltrates, Kaposi sarcoma, and pseudoverrucous papules and nodules. However, the main differential diagnosis includes Jacquet erosive diaper dermatitis, which is thought to be related to prolonged contact with urine and feces under occlusion. This diaper dermatitis is not age specific.

Although pseudoverrucous papules and nodules, Jacquet erosive diaper dermatitis, and granuloma gluteale infantum are clinically well defined, some patients show overlapping features (4-6). As distinct from Jacquet dermatitis, granuloma gluteale is more likely to occur in

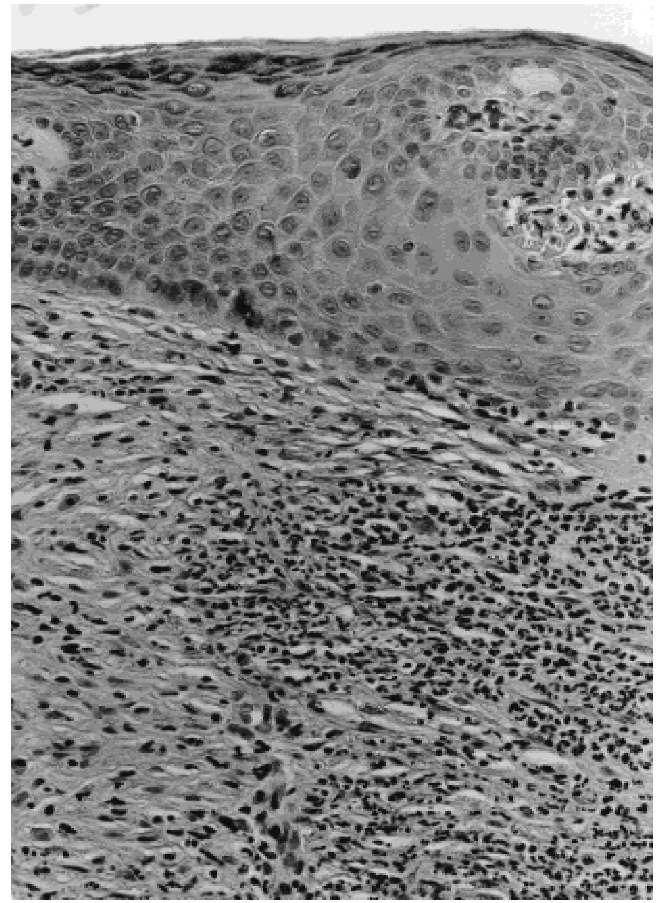

Figure 3. Infiltrates of polymorphic eosinophils, plasma cells, lymphocytes, and histiocytes are seen in the upper and middermis situated around newly formed capillaries in scarlike fibrous tissue. No granulomatous inflammation with typical epithelioid macrophages was found. (Hematoxylin and eosin; original magnification 200x.)

younger patients and is not exclusive to the incontinent. Granuloma gluteale can be distinguished from pseudoverrucous nodules on the basis of the dense dermal infiltrate seen on histologic examination; this is absent in pseudoverrucous papules and nodules (7).

In granuloma gluteale infantum a dense dermal inflammatory infiltrate of neutrophils, lymphocytes, plasma cells, and eosinophils is found. These histologic features are generally characteristic enough to exclude the other conditions mentioned above that have a similar clinical appearance. Fungal elements are not often seen, but Candida albicans may be cultured from the lesions (8).

The term "granuloma" indicates a clinical morphologic appearance rather than a strict histologic pattern. Multinucleated histiocytes or well-developed granulomas are not a feature of the infiltrate. The name granuloma gluteale infantum can thus be considered as a misnomer.

The pathogenesis of granuloma gluteale infantum has not been established. However, several causes have been proposed, including the view that the condition arises as a complication of primary irritant diaper dermatitis. According to Bonifazi et al. (2), there is no correlation between the severity of the preexisting diaper dermatitis and the development of the "granulomatous" lesions. 
Furthermore, plastic pants, diapers, and the use of topical corticosteroids to treat diaper dermatitis are believed to be possible precipitating factors $(2,9)$. A third possible cause could be Candida albicans, but this organism has not been isolated any more often in infants with gluteal granuloma than in uncomplicated cases of diaper dermatitis (10).

As far as the treatment of granuloma gluteale infantum is considered, the use of topical corticosteroids is controversial. In two patients, flurandrenolideimpregnated tape was tried with benefit (11); however, in many other cases, including our patient, the lesions have resolved without the use of corticosteroids. Others reported an increase in lesion size after topical steroid application (12) and even induction of granuloma gluteale infantum by steroids. Topical steroids should not be used in the diaper area for granuloma gluteale infantum because they may cause atrophy and other undesirable local effects.

When granuloma gluteale is related to proved Candida infection, antifungal treatment is indicated. In our patient the inflammation started after a Candida infection, which had already been treated by antifungal therapy without the use of any topical corticosteroid.

According to Schachner and Hansen (13) and Uyeda et al. (14), the best way to treat this condition is simply to keep the diaper area clean, remove the irritants, and not use any topical medication. Resolution of the lesions is said to occur over 1-2 months, leaving an atrophic scar.

Granuloma gluteale infantum is considered to be a complication of primary irritant diaper dermatitis that spontaneously regresses in 1-2 months. We report this patient in order to draw attention to this rare entity. It is important to recognize granuloma gluteale infantum, as it may resemble a neoplastic process.

\section{ACKNOWLEDGMENTS}

We would like to thank Dr. H. E. Menke of the Department of Dermatology and Drs. V. Noordhoek Hegt and
J. C. Verhaar of the Department of Pathology for their support and proofreading of the manuscript.

\section{REFERENCES}

1. Tappeiner J, Pfleger L. Granuloma gluteale infantum. Hautarzt 1971;22:383-388.

2. Bonifazi E, Garofalo L, Lospalluti M, et al. Granuloma gluteale infantum with atrophic scars: clinical and histological observations in eleven cases. Clin Exp Dermatol 1981;6:23-29.

3. Hamada T. Granuloma intertriginosum infantum (granuloma gluteale infantum) [letter]. Arch Dermatol 1975;111: 1072-1073.

4. Wilkinson S, Goldman L. Granuloma gluteale infantum. Cutis 1981;28:644-648.

5. Pierini AM. Letter to the editor. Cutis 1983;31:489.

6. Mohri N, Tomigawa M. Granuloma gluteale infantum [abstract; in Japanese]. Jpn J Dermatol 1987;88:656.

7. Goldberg NS, Esterly NB, Rothman KF, et al. Perianal pseudoverrucous papules and nodules in children. Arch Dermatol 1992;128:240-242.

8. Bluestein J, Furner BB, Phillips D. Granuloma gluteale infantum: case report and review of the literature. Pediatr Dermatol 1990;7:196-198.

9. Bazex A, Dupre A, Christol B, et al. Le granulome gluteal infantile (Tappeiner et Pfleger): faut-il le concevoir comme des "fluorides vegetantes de contact" ou des "halogenides du nourisson." Ann Dermatol Syphilol 1973;99:121-133.

10. Delacretaz J, Grigoriu D, De Crousaz H, et al. Candidose nodulaire de la region inguino-genitale et des fesses (granuloma gluteale infantum). Dermatologica 1972;144: 144-155.

11. Kikuchi I, Jono M. Fluranderenolide-impregnated tape for granuloma gluteale infantum [letter]. Arch Dermatol 1976; 112:564.

12. Lever WF. Histopathology of the skin, 8th ed. Philadelphia: JB Lippincott, 1997:335-340.

13. Schachner LA, Hansen RC. Pediatric dermatology, 2nd ed. New York: Churchill Livingstone, 1995.

14. Uyeda K, Nakayasu K, Takaishi Y, et al. Kaposi sarcomalike granuloma on diaper dermatitis. Arch Dermatol 1973; 107:605-607. 